\title{
Review
}

\section{Potential of cranberry for suppressing Helicobacter pylori, a risk factor for gastric cancer}

\author{
Amy B. Howell* \\ Marucci Center for Blueberry Cranberry Research, Rutgers, The State University of New Jersey, \\ Chatsworth, NJ, USA
}

Received 4 December 2018; accepted 11 January 2019

\begin{abstract}
This review summarizes the mechanistic and clinical research on the use of cranberry as an alternative management strategy for $H$. pylori bacteria in populations at high risk for infection-induced peptic ulcers and gastric cancer. The multiple mechanisms of action of cranberry polyphenols and how they may be applied in relation to what is known about the pathogenicity of $H$. pylori offers opportunity for utilizing this fruit to potentially help lower the incidence of ulcers and concomitant gastric cancer.
\end{abstract}

Keywords: Cranberry, Helicobacter pylori, suppression, antibiotic resistance, ulcers, stomach cancer

\section{Introduction}

Stomach (gastric) cancer is the fifth most common type of cancer worldwide for both sexes and all ages, according to the World Health Organization (WHO). By far, China has the highest incidence of stomach cancer with 500,000 new cases (out of the 1 million new cases globally) and nearly 400,000 deaths in 2018 alone. Infection with the bacterium Helicobacter pylori (H. pylori) is highly associated with development of most gastric ulcers [1] and, if untreated, individuals have a 3- to 6-fold increased risk of developing stomach cancer and mucosal associated-lymphoid-type (MALT) lymphoma [2]. Eradicating this bacterium with aggressive antibiotic regimens has historically been a strategy for decreasing the incidence of cancer [3]; however, increasing resistance rates and other barriers to antibiotic treatment have become problematic [4], fueling an interest in utilizing alternative control measures. There is also evidence that colonization with $H$. pylori may offer some specific health benefits in certain situations, calling into question the strategy of eradication through the administration of aggressive antibiotic regimens. There are a number of health benefits associated with cranberry (Vaccinium macrocarpon Ait.), especially antibacterial. This review will examine the potential for using cranberry to manage H. pylori infections in an alternative way that may help curb antibiotic resistance and reduce worldwide stomach cancer incidence.

\footnotetext{
${ }^{*}$ Corresponding author: Amy B. Howell, Marucci Center for Blueberry Cranberry Research, Rutgers, The State University of New Jersey, 125A Lake Oswego Rd., Chatsworth, NJ 08215, USA. Tel.: +1 609726 1590/Ext. 4413; Fax: +1 609726 1593; E-mail: ahowell@njaes.rutgers.edu.
} 


\section{H. pylori prevalence and transmission}

H. pylori was first discovered in 1982 [5] and is one of the most important bacteria worldwide with prevalence rates of over $80 \%$ in some developing countries and $20-50 \%$ in industrialized countries [6]. About two-thirds of the world is infected with H. pylori. In the U.S., it is more prevalent among older adults, African Americans, Hispanics, and lower socioeconomic groups, according to the Center for Disease Control (CDC). H. pylori is a gram negative, highly flagellated, mobile, multi-strained bacteria with varying degrees of pathogenicity [7]. It infects people often in early childhood, by contact with saliva from an infected mother's mouth [8], or through consuming food or water contaminated with feces [9]. The bacteria can also survive in dental plaque [10], making kissing a possible mode of transmission. Crowded living conditions, poor hygiene and sanitation, and other infected family members are all risk factors for acquisition of $H$. pylori [11]. The bacteria tend to persist in the host for life unless treated with antibiotics. Some people who are infected with the bacteria are asymptomatic making them potential sources of infection.

\section{H. pylori and ulcers}

H. pylori infection is the primary cause of ulcers and is present in $30 \%$ to $50 \%$ of patients with gastric ulcers in the stomach and $50 \%$ to $70 \%$ of those with duodenal ulcers in the upper intestines [12]. Ulcer risk also increases by use of non-steroidal anti-inflammatory drugs (especially among the elderly), alcohol consumption, cigarette smoking [13], and high salt diet [14]. When H. pylori enters the body, it synthesizes and secretes urease enzyme which produces ammonia and carbon dioxide that neutralize stomach acid, helping the bacteria survive the acidic conditions in the stomach. The lining of the stomach has a thick, protective mucus layer that functions as a physical barrier. To cause an ulcer, $H$. pylori must leave the mucus layer and adhere to the underlying stomach epithelium. When the bacteria reach this viscous mucus layer, they use their polar flagella to swim through it to reach the gastric epithelium where they adhere to the underlying stomach cells via sialic acid-binding adhesin (SabA) and other adhesins [12]. Adherence of $H$. pylori to gastric epithelial cells, which is mediated by about 10 different adhesins, is a crucial initial step in colonization and establishment of chronic infection [15]. The ability of the bacteria to express different combinations of adhesins with distinct specificities determines whether they will attach to the epithelium or remain in the mucus [16]. The bacteria must take hold quickly to avoid being swept into the intestine. Only a small percentage $(<1 \%)$ of the total $H$. pylori population adheres to the gastric epithelium while the remainder of the population stays in the gastric mucus layer or is removed from the body by peristalsis or other mechanisms [17]. The bacteria living in the gastric mucus may act as a reservoir of infection for the underlying cells, which is essential for the development of disease. The bacteria are protected by the mucus layer, allowing them to multiple freely and readily mutate. They deliver a highly immunogenic protein, cytotoxin-associated gene $\mathrm{A}(\mathrm{CagA})$ to epithelial cells which activates the inflammatory and immune responses in the host [18]. Chronic inflammation induced by H. pylori damages the mucosa and disrupts $\mathrm{pH}$ regulation, allowing acid to attack the stomach lining leading to ulcer formation. Ulcer symptoms normally include gnawing and burning pain, nausea, vomiting, bloating and heartburn; and, in serious cases, ulcers may cause bleeding into the stomach or perforation of the gastrointestinal wall [12].

\section{H. pylori and stomach cancer}

H. pylori infection has been implicated as the greatest risk factor for the development of stomach cancer [19]. In fact, in 1994, the WHO classified H. pylori as a class I carcinogen [20]. Infection with Cag-A-positive strains of the bacteria further increases the risk for stomach cancer over the risk of infection with non-Cag-A strains [21]. Thus, eradication of the bacteria with antibiotics has been strongly encouraged by the CDC and the WHO. 
Randomized controlled studies have shown that a decrease in the progression and a regression of precancerous lesions is possible by eradicating $H$. pylori [22]. The American College of Gastroenterology published clinical guidelines in 2017 for the treatment of $H$. pylori recommending as first-line treatment either a combination of three antibiotics and a proton pump inhibitor (PPI), or bismuth quadruple therapy which uses a bismuth preparation to reduce gastrointestinal acidity, two antibiotics, and a PPI [23]. PPIs block the secretion of stomach acids and can enhance the efficacy of antibiotics used to eradicate the bacteria [24]. However, conventional triple or quadruple antibiotic therapy to eradicate the bacteria can be quite harsh, has numerous side-effects and can promote selection for antibiotic resistant strains of $H$. pylori [25]. Clarithromycin-based triple therapy was initially established in the 1990s and resistance to it has increased steadily ever since, as has resistance to levofloxacin, which was proposed as an alternative to clarithromycin. In 2012, treatment failure rate for triple therapy was over $20 \%$ worldwide, due to antibiotic resistance [26]. Salvage therapy is sometimes used when initial therapy fails; this strategy uses different antibiotics that may not be resistant. Bismuth quadruple therapy or regimens containing levofloxacin are preferred salvage regimens but are also losing potency [23]. In addition to antibiotic resistance, poor compliance is an obstacle to effective treatment. Triple and quadruple therapies are complicated, expensive, and can cause serious digestive side effects [27]. In many countries, the barriers to treatment of $H$. pylori are so significant that the bacteria persist and increase the risk of developing stomach cancer in the future. Therefore, it is critical to identify other potentially effective alternative strategies to manage infections which are safe, cost-effective and will not lead to antibiotic resistance issues.

\section{Co-evolution of $\boldsymbol{H}$. pylori and humans}

Some research suggests that complete eradication of $H$. pylori may not be desirable because colonization with Cag-positive strains may be protective in some cases against asthma, allergy, inflammatory bowel disease, gastroesophageal reflux disease (GERD), and esophageal cancer [28, 29]. But, the association is not well-defined. H. pylori has inhabited the human digestive tract for more than 50,000 years [27], however the existence of ulcers is thought to be a more recent phenomenon in the past 200 years, associated with changes in diet and lifestyle [30]. Some researchers believe that the co-evolution of $H$. pylori with the human population might actually have positive health effects in some circumstances [31]. Thus, to avoid losing the possible benefits of $H$. pylori colonization while reducing the risk factors for ulcers and stomach cancer, a potentially beneficial strategy might be to utilize dietary interventions aimed at suppression of the bacteria rather than total eradication [32]. Diet-based treatments could potentially eliminate gastrointestinal side-effects, resistance issues and cost barriers associated with antibiotics, and help preserve probiotic species within the gut microbiome.

\section{Potential of cranberry for management of $\boldsymbol{H}$. pylori infection}

The American cranberry (Vaccinium macrocarpon Ait.), a fruit native to North America, has a long history of use for medicinal purposes, including prevention of urinary tract infections (UTIs), lowering oxidative stress and inflammation, and reducing risk factors for heart disease [33]. The first mention of cranberry in connection with ulcers was by Felter and Lloyd (1905), in their King's American Dispensatory, where they say the fruit was used for "malignant ulcers." In recent studies, cranberry has been tested in both in vitro and clinical trials and shows promise as a non-pharmacological treatment to manage $H$. pylori infections [34].

Cranberries contain a number of phytochemicals that have bioactive properties when consumed, including proanthocyanidins (PACs), anthocyanin pigments, flavonol glycosides, and certain acids [33]. The cranberry proanthocyanidins with unusual A-type double linkages [35], have been widely studied for their multiple biological activities, including prevention of adhesion of P-fimbriated uropathogenic Escherichia coli to bladder cells, oral bacteria to tooth surfaces and $H$. pylori to stomach cells [36]. This bacterial anti-adhesion effect that 
is active against multiple infection sites in the body is significant because the PACs are not killing the bacteria as antibiotics would, but rather inhibiting an initial step in the infection process, reducing the likelihood of resistant bacterial strain development [37]. Use of low-dose antibiotic regimes to prevent bacterial infections, especially UTIs, has led to increasing resistance to both first and second-line antibiotics used for treatment of these infections [38]. Cranberry has been recommended as an alternative therapy for prevention of UTI, which could slow the pace of antibiotic resistance development by reducing the ultimate need for antibiotic treatments. Use of cranberry to manage $H$. pylori infections could potentially help curb the antibiotic resistance issues that are also on the rise when triple or quadruple therapy is used to treat $H$. pylori. Consuming cranberry on a regular basis could potentially reduce the incidence of stomach cancer by suppressing the bacteria and the ulcerative symptoms in a more gentle and natural way, without completely eradicating the bacteria.

\section{Bacterial anti-adhesion activity}

A method for studying the adhesion of $H$. pylori to the gastric mucus [39] has been utilized in research to test the anti-adhesion activity of cranberry. An in vitro study in Israel was the first to determine that cranberry could prevent adherence of $H$. pylori to mucus and stomach cells [40]. Since the bacteria initially colonize the gastric mucus and must then attach to the underlying gastric epithelium to cause ulcerative disease, the researchers hypothesized that if cranberry could inhibit adhesion of the bacteria to the mucus, it might prevent their eventual attachment to the underlying epithelial cells. They found that a non-dialyzable extract of cranberry (NDM) containing predominantly PACs was able to prevent sialic acid-specific adhesion of three strains of H. pylori to human gastric mucus and human erythrocytes. They also preincubated the cranberry extract with mucus and found that bacterial adhesion was not affected. Additionally, they were unable to detach bacteria from the mucus once it had adhered. These experiments indicate that the cranberry compounds were acting directly on the bacteria to bring about the anti-adhesion activity, at a concentration similar to that found in some commercial cranberry juice drinks containing about $27 \%$ cranberry and in some dried juice-based encapsulated cranberry extracts [35].

Another study determined the sensitivity of 83 antibiotic-resistant and nonresistant $H$. pylori isolates to the anti-adhesion effect of the PAC-rich NDM cranberry extract [41]. The adhesion of 53 out of 83 isolates derived from either antibiotic-treated or untreated patients was inhibited by the same concentration $(0.2 \mathrm{mg} / \mathrm{mL})$ of the NDM extract. There was no relationship between resistance to the anti-adhesion effect of this extract and antibiotic resistance, suggesting that combining the cranberry extract and antibiotic may improve bacterial eradication.

\section{Bacterial growth inhibition}

An in vitro study tested the ability of cranberry and other fruit extract powders alone or in combination with the antibiotic clarithromycin to eradicate H. pylori [42]. A pathogenic strain (ATCC strain 49503) was tested that produces a cytotoxin responsible for gastric damage. The cranberry extract was incubated for 18 hours with the bacteria and bactericidal effects were observed at the $0.5 \%$ cranberry concentration, and significantly greater $(p<0.05)$ effects occurred when clarithromycin was added. The 18-hour incubation time was long and may not be analogous to an in vivo situation where the transit time of the cranberry extract through the stomach is likely to be shorter.

Dose-dependent bacterial growth inhibition of two H. pylori strains by cranberry and its polyphenolic fraction was demonstrated in another in vitro study [43]. Nearly complete bacterial inhibition was achieved with cranberry extract at $3.3 \mathrm{mg} / \mathrm{mL}$ in both liquid culture and on plated culture media. To determine the active fractions, cranberry juice concentrate (35 Brix) was separated by column chromatography into an organic acid/sugar 
and a polyphenolic fraction and the bacterial growth inhibition study was repeated. Results indicated that the polyphenolic fraction was responsible for suppressing bacterial proliferation. In addition, when $H$. pylori was incubated for 2 days with $2 \%$ cranberry juice or cranberry extract powder at $1 \mathrm{mg} / \mathrm{mL}$, the bacteria developed a coccoid form at a 3 -fold higher rate than the control. The researchers speculated that the morphological changes in the bacteria may be responsible for the growth inhibition observed in the previous studies, since the coccoid form is thought to be nonmotile and therefore possibly unable to multiply [44].

In a follow-up study, Matsushima et al. (2013) tested the growth inhibiting activity of cranberry extract against 27 additional strains of $H$. pylori that were collected and cultured from the stomach mucosa of clinical patients with either peptic ulcer, MALToma or gastritis. Growth inhibition on agar plate cultures containing cranberry at concentrations of less than $2 \mathrm{mg} / \mathrm{mL}$ was demonstrated with 6 of the 27 bacterial strains, indicating that the inhibitory activity was strain-specific.

Another study tested cranberry and oregano powders at different concentrations and ratios in agar diffusion plate assays to try and develop a specific phenolic antioxidant profile to inhibit $H$. pylori [45]. Mixtures containing $25 \%$ (wt/wt) oregano with $75 \%(\mathrm{wt} / \mathrm{wt})$ cranberry with $0.1 \mathrm{mg}$ total phenolics per disk exhibited the greatest antimicrobial activity against $H$. pylori. Urease inhibition and disruption of energy production by inhibition of proline dehydrogenase at the plasma membrane were suggested to be the modes of action. The researchers speculated that designing specific phenolic profiles to inhibit $H$. pylori could potentially be feasible.

\section{Anti-inflammatory activity}

Suppression of gastric inflammation mediated by cytokines secreted by stomach cells is another possible strategy for $H$. pylori inhibition. One in vitro study utilized a stomach cancer cell line (MKN45) and H. pylori strains obtained from patients with ulcers, gastritis or MALToma to study the effect of cranberry on suppression of IL-8 secretion in the stomach [43]. Cranberry powdered extract containing cranberry juice concentrate with $5.4 \%$ total polyphenols and $11.2 \%$ total organic acids inhibited interleu-kin-8 secretion from stomach cells at $1 \mathrm{mg} / \mathrm{mL}$ in the majority of $H$. pylori strains. Activity appeared to be strain independent.

\section{H. pylori clearance, eradication and prevention in mice}

A trial was undertaken in which mice were tested to determine if cranberry could prevent $H$. pylori infection and treat existing infection [46]. In the therapeutic trial, mice (strain SS1) were infected with an antibiotic-sensitive H. pylori strain and after 2 weeks were put into one of four groups and challenged with either: cranberry juice at $0.5 \mathrm{~mL} /$ mouse for 30 days, triple antibiotic therapy for 14 days, cranberry plus triple therapy, or untreated infected control. A subset of the mice was sacrificed at 24 hours and at 4 weeks and the bacteria quantified. After 24 hours on the cranberry juice, mice had a significant $(p<0.01)$ bacterial clearance rate of $80 \%$. When the cranberry was administered with the triple antibiotic therapy, the clearance rate increased to $90 \%$. The antibiotic triple therapy alone cleared $100 \%$ of the bacteria. The $H$. pylori eradication rates 4 weeks later were $20 \%$ for the cranberry juice group, and $80 \%$ for both the antibiotic + cranberry and antibiotic alone groups. Therefore, the triple antibiotic treatment was not enhanced by the addition of cranberry juice. The cranberry was able to quickly clear the bacteria within 24 hours, but the bacterial population returned a month after the cessation of cranberry. Additional studies should be undertaken to determine if the high bacterial clearance rates could be maintained with daily, or more regular cranberry consumption.

In the prevention trial, mice were fed cranberry juice for 30 days, and then challenged with $H$. pylori alone or combined with juice [46]. After 2 weeks, the mice were sacrificed and assessed for infection status. Cranberry juice was not effective at preventing $H$. pylori infection in these mice. 
Table 1

Clinical trials on consumption of cranberry to suppress or eradicate Helicobacter pylori infections

\begin{tabular}{|c|c|c|c|c|c|}
\hline Reference & $\begin{array}{l}\text { Study } \\
\text { design }\end{array}$ & $\begin{array}{l}\text { Patient } \\
\text { population }\end{array}$ & $\begin{array}{l}\text { Product and } \\
\text { daily dosage }\end{array}$ & $\begin{array}{l}\text { Treatment } \\
\text { duration }\end{array}$ & Outcome \\
\hline $\begin{array}{l}\text { Zhang et al. } \\
2005\end{array}$ & DBRPCT & $\begin{array}{l}\text { HP-positive } \\
\quad \text { adults, } n=189\end{array}$ & $\begin{array}{l}\text { CJC } 240 \mathrm{~mL} \text { bid, or } \\
\text { placebo }\end{array}$ & 3 months & $\begin{array}{l}\text { Significant Hp suppression in CJ group } \\
\text { vs placebo }(p<0.05)\end{array}$ \\
\hline $\begin{array}{l}\text { Gotteland } \\
\text { et al. } 2008\end{array}$ & DBRPCT & $\begin{array}{l}\text { Children, } \\
\begin{array}{l}\text { Hp-positive, } \\
n=295\end{array}\end{array}$ & $\begin{array}{l}\text { CJ } 200 \mathrm{~mL}, \mathrm{La} 1 \\
80 \mathrm{~mL} \text { alone and } \\
\text { combined, or } \\
\text { placebo }\end{array}$ & 3 weeks & $\begin{array}{l}\text { Significant Hp eradication at } 3 \text { wks in } \\
\text { CJ and La1 vs placebo }(p<0.01) \text {, but } \\
\text { no synergistic effects. Participants } \\
\mathrm{Hp}+1 \text { month after intervention }\end{array}$ \\
\hline $\begin{array}{l}\text { Shmuely et al. } \\
\qquad 2007\end{array}$ & DBRPCT & $\begin{array}{l}\text { Hp-positive adults } \\
\text { treated with TT, } \\
n=177\end{array}$ & $\begin{array}{l}\text { CJ } 250 \mathrm{~mL} \text { combined } \\
\text { with TT or TT } \\
\text { combined with } \\
\text { placebo }\end{array}$ & 2 weeks & $\begin{array}{l}\text { Significantly higher eradication in } \\
\text { women in CJ/TT arm vs TT alone } \\
(p=0.03)\end{array}$ \\
\hline $\begin{array}{l}\text { Seyyedmajidi } \\
\text { et al. } 2016\end{array}$ & PRCT & $\begin{array}{l}\text { Hp-positive adults } \\
\text { with PUD, } \\
n=200\end{array}$ & $\begin{array}{l}500 \text { mg CEP bid } \\
\text { combined with TT } \\
\text { or TT alone }\end{array}$ & 2 weeks & $\begin{array}{l}\text { Significantly higher eradication in } \\
\text { CEP + TT arm vs TT alone } \\
(p=0.042) 6 \text { weeks after } \\
\text { intervention }\end{array}$ \\
\hline
\end{tabular}

$\mathrm{DB}=$ double blind; $\mathrm{R}=$ randomized; $\mathrm{P}=$ prospective; $\mathrm{CT}=$ controlled trial; $\mathrm{PCT}=$ placebo-controlled; CJC $=$ Cranberry Juice Cocktail ${ }^{\circledR}$ (Ocean Spray ${ }^{\circledR}, \mathrm{CJC} \sim 27 \%$ cranberry juice); $\mathrm{CJ}=$ cranberry juice of unknown concentration from unknown manufacturer; $\mathrm{CEP}=$ cranberry extract powder; $\mathrm{La1}=$ Lactobacillus johnsonii $\mathrm{La} 1, \mathrm{HP}=$ Helicobacter pylori $; \mathrm{TT}=$ antibiotic triple therapy, $\mathrm{PUD}=$ peptic ulcer disease .

\section{Human clinical trials}

Four human intervention trials, to date, have demonstrated significant clinical effects of cranberry against H. pylori, both with and without concomitant antibiotic therapy (Table 1). The first trial designed to study the effects of cranberry on $H$. pylori infection was conducted in a rural area in Shandong Province in China with one of the world's highest prevalence rates of gastric cancer [47]. In this area, $72 \%$ of adults and $52 \%$ of children aged 3-4 were positive in a breath test for $H$. pylori infection at the time of the trial in 2005 . All 189 participants in the double-blind randomized, placebo-controlled trial (RCT) tested positive for $H$. pylori infection at the time of enrollment. They were divided into two groups and assigned to either a treatment group that consumed two daily servings of a $250-\mathrm{ml}$ cranberry juice cocktail drink (27\% juice) or a placebo juice for 90 days. The overall average compliance rate among cranberry treatment and placebo recipients was $85 \%$. Using ${ }^{13} \mathrm{C}$ urea breath analysis, they found that the overall rate of $\mathrm{H}$. pylori suppression at 35- and 90-day intervals was significantly higher $(p<0.05)$ in the cranberry group $(14.3 \%)$ compared to placebo $(5.2 \%)$. The actual bacterial numbers in the gastric mucosa were not determined in each individual before and after cranberry treatment, so it was not possible to make quantitative comparisons of any changes in $H$. pylori load. The authors speculated that because the prevalence rate of $\mathrm{H}$. pylori infection was $72 \%$ in the adult population in this area of China, the $14.3 \%$ decrease in the infection rate in this trial could have a significant impact on the spread of infection and thereby potentially lower the risk of stomach cancer.

Probiotics have been studied for the management of $H$. pylori colonization due to their production of organic acids and bacteriocins which have been shown to inhibit bacterial growth and attachment to stomach cells [48]. The effects of Lactobacillus johnsonii La1, a probiotic that can stimulate the immune system, administered in combination with cranberry was investigated in a multicentric, double-blind RCT in Chile [49], a country where about $60 \%$ of adolescents and $35 \%$ of children are colonized with $H$. pylori [50]. Participants were 295 children ages 6-16 who were positive for $H$. pylori, but were asymptomatic. Treatment products were administered 
to the children during school for a period of 3 weeks. One group drank $200 \mathrm{~mL}$ of cranberry juice (4\% v/v prepared from concentrate) daily, another was given an $80 \mathrm{~mL}$ drink containing the L. johnsonii La1 probiotic supplement at a concentration of $>10^{7}$ colony-forming units $/ \mathrm{mL}$, another consumed a drink with both cranberry and the probiotic, and another received a placebo. At the end of the 3-week intervention period, the children were tested for the presence of $\mathrm{H}$. pylori. Bacterial eradication rates were significantly higher for all treatment groups compared to controls $(p<0.01)$, with $14.9 \%$ for the probiotic group, $16.9 \%$ for the cranberry juice group, $22.9 \%$ for the cranberry juice/probiotic combination group, and $1.5 \%$ for the placebo group. No significant synergistic inhibitory effect on $H$. pylori colonization was observed for the combination of cranberry juice and probiotic. After a 1-month wash-out period, inhibition was tested again in a subgroup of those that were $H$. pylori-negative at 3 weeks. The group had an $80 \%$ infection rate indicating that the bacteria were not completely eradicated. The researchers speculated that maintaining $H$. pylori suppression may be possible by ingesting cranberry on a regular basis.

The in vitro work by Shmuely et al. (2005) demonstrated an improvement in H. pylori eradication rates when a PAC-rich NDM extract was combined with antibiotics. The potential additive effects of cranberry and antibiotic therapy were then investigated in a human double-blind RCT [51], in which 177 participants were treated for existing H. pylori infection with triple therapy consisting of two antibiotics (amoxicillin and clarithromycin), plus a proton pump inhibitor (omeprazole) for one week. Half the group was then administered cranberry juice $(250 \mathrm{~mL})$ or a placebo twice daily for another two weeks. The overall eradication rate was $82.5 \%$ for all 3 arms. Although there was no significant difference in $H$. pylori eradication rates among the groups, analysis by gender revealed a significantly $(p=0.03)$ greater eradication rate in females in the cranberry-antibiotic arm compared to triple therapy alone, suggesting an additive effect. Since resistance to clarithromycin has been increasing worldwide [9], the addition of cranberry may have increased bacterial susceptibility enough to elicit a significant increase in bacterial eradication in the female study participants.

Another human trial (prospective, open-label, randomized clinical) conducted in Iran in 2016 compared the H. pylori eradication rate of triple therapy (lansoprazole, clarithromycin, and amoxicillin (LCA)) combined with cranberry to triple therapy alone [52]. Two hundred participants between the ages of 23 and 77 diagnosed with peptic ulcer disease were randomized into two groups, one group took LCA triple therapy twice daily for 2 weeks, while the other group took the same LCA treatment combined with $500 \mathrm{mg}$ of encapsulated cranberry powder for 2 weeks. Six weeks after the trial was completed, eradication rates were determined using ${ }^{13} \mathrm{C}$-urea breath testing. The second group treated with the triple therapy-cranberry combination had a significantly higher $(p=0.042)$ eradication rate of $89 \%$ than the group treated with triple therapy alone (74\%). Again, this demonstrated an additional benefit when cranberry was administered along with antibiotic triple therapy.

\section{Summary}

The association of $H$. pylori with humans appears to be a complex one, dating back tens of thousands of years when it may have conferred only beneficial effects on the gut, esophagus and immune system, with deleterious gastric ulcers and stomach cancer developing much more recently as diets and lifestyles changed [30]. The use of conventional approaches to treatment using aggressive antibiotic therapies to completely eradicate the bacteria have been somewhat successful, resulting in worldwide decreases in $H$. pylori prevalence; but, these strategies have been continually challenged with obstacles to treatment and increasing antibiotic resistance rates. In many countries, like China, where $H$. pylori colonization has led to staggering incidences of peptic ulcer disease and stomach cancer deaths, the barriers to successful eradication are enormous.

Cranberry has demonstrated anti-H. pylori properties in in vitro, animal, and clinical models which indicate that cranberry consumption alone or administered with antibiotics, can reduce H. pylori colonization but may not fully eradicate it. It is in places like China where alternative strategies should be tested, such as consuming cranberry on a regular and sustained basis to facilitate continued bacterial suppression through multiple modes of 
action, including bacterial growth inhibition, anti-adhesion activity, enzyme inhibition, morphological changes and host anti-inflammatory activity which have been presented in this review. Additional mechanistic and clinical research into the benefits of cranberry in the management of $\mathrm{H}$. pylori-induced disease is warranted to determine effective doses and delivery forms that are acceptable to different cultures.

\section{Acknowledgments}

The authors have no acknowledgments.

\section{Funding}

The authors report no funding.

\section{Conflict of Interest}

The authors have no conflict of interest to report.

\section{References}

[1] Correa P. Human gastric carcinogenesis: A multistep and multifactorial process-first American Cancer Society Award lecture on cancer epidemiology and prevention. Cancer Res. 1992;52(24):6735-40.

[2] Helicobacter pylori Fact Sheet for Health Care Providers, Center for Disease Control, 1998.

[3] Uemura N, Okamoto S, Yamamoto S, Matsumura N, Yamaguchi S, Yamakido M, et al. Helicobacter pylori infection and the development of gastric cancer. N Engl J Med. 2001;345:784-9.

[4] Graham DY, Fischbach L. Helicobacter pylori treatment in the era of increasing antibiotic resistance. Gut. 2010;59:1143-53. doi: 10.1136/gut.2009.192757

[5] Marshall BJ, Warren JR. Unidentified curved bacilli in the stomach of patients with gastritis and peptic ulceration. Lancet. 1984;1: 1311-15.

[6] Torres J, Leal-Herrera Y, Perez-Perez G, Gomez A, Camorlinga-Ponce M, Cedillo-Rivera R, et al. A community based seroepidemiologic study of Helicobacter pylori infection in Mexico. J Infect Dis. 1998;178(4):1089-94.

[7] Linz B, Balloux F, Moodley Y, Manica A, Liu H, Roumangnac P, et al. An African origin for the intimate association between humans and Helicobacter pylori. Nature. 2007;445:915-8.

[8] Veres G, Pehlivanoglu E. Helicobacter pylori infection in pediatrics. Helicobacter. 2007;12:38-44.

[9] Megraud F. Transmission of Helicobacter pylori: Faecaloral versus oral-oral route. Aliment Pharmacol Ther. 1995;9:85-91.

[10] Ogunbodede E, Lawal O, Lamikanra A, Okeke I, Rotimi O, Rasheed A. Helicobacter pylori in the dental plaque and gastric mucosa of dyspeptic Nigerian patients. Trop Gastroenterol. 2002;23(3):127-33.

[11] Vincent P, Gottrand F, Pernes P, Husson MO, Lecomtehoucke M, Turck D, et al. High prevalence of Helicobacter pylori infection in cohabiting children—epidemiology of a cluster, with special emphasis on molecular typing. Gut. 1994;35:313-6.

[12] Kusters JG, van Vliet AHM, Kuipers EJ. Pathogenesis of H. pylori infection. Clin Microbiol Rev. 2006;19(3):449-90. doi: 10.1128/CMR.00054-05

[13] Pan KF, Zhang L, Gerhard M, Ma JL, Liu WD, Ulm K, et al. A large randomised controlled intervention trial to prevent gastric cancer by eradication of Helicobacter pylori in Linqu County, China: Baseline results and factors affecting the eradication. Gut. 2016; 65:9-18.

[14] Zhu Y, Zhou X, Wu J, Su J, Zhang G. Risk factors and prevalence of Helicobacter pylori infection in persistent high incidence area of gastric carcinoma in Yangzhong City. Gastroenterol Res Pract. 2014; Article ID 481365, 10 pages. doi: 10.1155/2014/481365

[15] Wadstrom T, Hirmo S, Nilsson B. Biochemical aspects of H. pylori adhesion. J Physiol Pharmacol. 1997;48,325-31. 
[16] Dorell N, Crabtree JE, Wren BW. Host-bacterial interactions and the pathogenesis of Helicobacter pylori infection. Trends Microbiol. 1998;6:379-81.

[17] Hazell SL, Lee A, Brady L, Hennessy W. Campylobacter pyloridis and gastritis: Association with intracellular spaces and adaptation to an environment of mucus as important factors in colonization of the gastric epithelium. J Infect Dis. 1986;153:658-63.

[18] Evans JE, Evans DG. Helicobacter pylori adhesins: Review and perspectives. Helicobacter. 2000;5:183-95.

[19] Suerbaum S, Michetti P. Helicobacter pylori infection. N Engl J Med. 2002;347(15):1175-86.

[20] Houghton J, Wang TC. Helicobacter pylori and gastric cancer: A new paradigm for inflammation-associated epithelial cancers. Gastroenterology. 2005;128(6):1567-78.

[21] Huang Y, Wang QL, Cheng DD, Xu WT, Lu NH. Adhesion and invasion of gastric mucosa epithelial cells by Helicobacter pylori. Front Cell Infect Microbiol. 2016;6:159.

[22] Zhou L, Sung JJ, Lin S, Jin Z, Ding S, Huang X, et al. A five-year follow-up study on the pathological changes of gastric mucosa after H. pylori eradication. Chin Med J (Engl). 2003;116(1):11-4.

[23] Chey WD, Leontiadis GI, Howden CW, Moss SF. ACG clinical guideline: Treatment of Helicobacter pylori infection. Am J Gastroenterol. 2017;112(2):212-39.

[24] Lin T-F, Hsu P-I. Second-line rescue treatment of Helicobacter pylori infection: Where are we now? World J Gastroenterol. 2018;24(40):4548-53. doi: 10.3748/wjg.v24.i40.4548

[25] Vakil N. Helicobacter pylori: Factors affecting eradication and recurrence. Am J Gastroenterol. 2005;100(11):2393-4.

[26] Safavi M, Sabourian R, Foroumadi A. Treatment of Helicobacter pylori infection: Current and future insights. World J Clin Cases. 2016;4(1):5-19.

[27] Owyang SY, Luther J, Kao JY. Helicobacter pylori: Beneficial for most? Expert Rev Gastroent. 2011;5(6):649-51.

[28] McNeil C. Helicobacter pylori: Good side complicates efforts to combat bad side. J Nat Can Instit. 2008;100(24):1748-50.

[29] Chen Y, Blaser MJ. Inverse associations of Helicobacter pylori with asthma and allergy. Arch Intern Med. 2007;167(8):821-7.

[30] Graham DY. History of Helicobacter pylori, duodenal ulcer, gastric ulcer and gastric cancer. World J Gastroenterol. 2014;20(18):5191204.

[31] Atherton JC, Blaser MJ. Coadaptation of Helicobacter pylori and humans: Ancient history, modern implications. J Clin Invest. 2009;119(9):2475-87.

[32] Fahey JW, Stephenson KK, Wallace AJ. Dietary amelioration of Helicobacter infection. Nutr Res. 2015;35(6):461-73. doi: 10.1016/j.nutres.2015.03.001

[33] Upton R, Brendlar T. American herbal pharmacopoeia and therapeutic compendium. Cranberry fruit Vaccinium macrocarpon Aiton. Revision. Standards of analysis, quality control, and therapeutics. Scotts Valley (CA): American Herbal Pharmacopoeia: 2002.

[34] Shmuely H, Domniz N, Yahav J. Non-pharmacological treatment of Helicobacter pylori. World J Gastrointest Pharmacol Ther. 2016;7(2):171-8. doi: 10.4292/wjgpt.v7.i2.171

[35] Howell AB, Botto H, Combescure C, Blanc-Potard AB, Gausa L, Matsumoto T, et al. Dosage effect on uropathogenic Escherichia coli anti-adhesion activity in urine following consumption of cranberry powder standardized for proanthocyanidin content: A multicentric randomized double blind study. BMC Infect Dis. 2010;10:94. doi: 10.1186/1471-2334-10-94

[36] Reed JD, Howell AB. Biological activity of cranberry proanthocyanidins: Effects on oxidation, microbial adhesion, inflammation, and health. In: Cooper R, Kronenberg F, editors. Botanical medicine from bench to bedside. New Rochelle (NY): Mary Ann Liebert; 2009. pp. 190-201.

[37] Ofek I, Hasty DL, Sharon N. Anti-adhesion therapy of bacterial diseases: Prospects and problems. FEMS Immunol Med Microbiol. 2003;38:181-91.

[38] Beerepoot M, Geerlings S. Nonantibiotic prophylaxis for recurrent urinary tract infections. Pathogens. 2016;5(2):36. doi: 10.3390/pathogens5020036

[39] Tzouvelekis LS, Mentis AF, Makris AM, Spiliadis C, Blackwell C, Weir DM. In vitro binding of Helicobacter pylori to human gastric mucin. Infect Immun. 1991;59(11):4252-4.

[40] Burger O, Ofek I, Tabak M, Weiss EI, Sharon N, Neeman I. A high molecular mass constituent of cranberry juice inhibits Helicobacter pylori adhesion to human gastric mucus. FEMS Immunol Med Microbiol. 2000;29(4):295-301.

[41] Shmuely H, Burger O, Neeman I, Yahav J, Samra Z, Niv Y, et al. Susceptibility of Helicobacter pylori isolates to the antiadhesion activity of a high-molecular-weight constituent of cranberry. Diagn Microbiol Infect Dis. 2005;50:231-5.

[42] Chatterjee A, Yasmin T, Bagchi D, Stohs SJ. Inhibition of Helicobacter pylori in vitro by various berry extracts, with enhanced susceptibility to clarithromycin. Mol Cell Biochem. 2004;265:19-26.

[43] Matsushima M, Suzuki T, Masui A, Kasai K, Kouchi T, Takagi A, et al. Growth inhibitory action of cranberry on Helicobacter pylori. JGH Open. 2008;23:S175-80. 
[44] Mizoguchi H, Fujioka T, Nasu M. Evidence for viability of coccoid forms of Helicobacter pylori. J Gastroenterol. 1999;34(Suppl. $\mathrm{XI}): 32-6$.

[45] Lin YT, Kwon YI, Labbe RG, Shetty K. Inhibition of Helicobacter pylori and associated urease by oregano and cranberry phytochemical synergies. Appl Environ Microbiol. 2005;71(12):8558-64.

[46] Xiao SD, Shi T. Is cranberry juice effective in the treatment and prevention of Helicobacter pylori infection of mice? Chin J Dig Dis. 2003;4:136-9.

[47] Zhang L, Ma J, Pan K, Go VL, Chen J, You WC. Efficacy of cranberry juice on Helicobacter pylori infection: A double-blind, randomized placebo-controlled trial. Helicobacter. 2005;10(2):139-45.

[48] Gotteland M, Brunser O, Cruchet S. Systematic review: Are probiotics useful in controlling gastric colonization by Helicobacter pylori? Aliment Pharmacol Ther. 2006;23(8):1077-86.

[49] Gotteland M, Andrews M, Toledo M, Muñoz L, Caceres P, Anziani A, et al. Modulation of Helicobacter pylori colonization with cranberry juice and Lactobacillus johnsonii La1 in children. Nutrition. 2008;24:421-6.

[50] Hopkins RJ, Vial PA, Ferreccio C, Ovalle J, Prado P, Sotomayor V, et al. Seroprevalence of Helicobacter pylori in Chile: Vegetables may serve as one route of transmission. J Infect Dis. 1993;168:222-6.

[51] Shmuely H, Yahav J, Samra Z, Chodick G, Koren R, Niv Y, et al. Effect of cranberry juice on eradication of Helicobacter pylori in patients treated with antibiotics and a proton pump inhibitor. Mol Nutr Food Res. 2007;51(6):746-51.

[52] Seyyedmajidi M, Ahmadi A, Hajiebrahimi S, Seyedmajidi S, Rajabikashani M, Firoozabadi M, et al. Addition of cranberry to proton pump inhibitor-based triple therapy for Helicobacter pylori eradication. J Res Pharm Pract. 2016;5:248-51. 